\title{
A FAMÍLIA E OS FILHOS NA CONSTITUIÇÃO ITALIANA ${ }^{1}$
}

\section{FAMILY AND CHILDREN IN THE ITALIAN CONSTITUTION}

\author{
LICIA CALIFANO
}

\begin{abstract}
RESUMO: Este artigo analisa o tratamento da família e dos filhos pela Constituição Italiana, descrevendo a lenta evolução da disciplina do direito de família nos últimos 200 anos. A matéria, primeiramente, era vista totalmente vinculada ao Direito Canônico. Com a separação da Igreja do Estado, contudo, a família passou a ter uma regulamentação civil, sobretudo, influenciada pelo Código Napoleônico. O Código Civil Italiano de 1942 marca uma fase de absoluto domínio do Estado sobre a família, servindo a instituição de base para o Regime Fascista. Esta fase é assinalada pelo autoritarismo do pai e pela visão tradicional de família, havendo distinção entre filhos frutos do casamento conjugal e filhos de relações não matrimoniais. Somente em tempos recentes, com a nova Constituição Italiana, a família passou a ser vista com valores plurais, admitindo-se direitos de igualdade aos filhos, independente se nascidos, ou não, de relações matrimoniais. Dentro desta evolução legislativa e cultural, o texto desenvolve o novo tratamento da família italiana.

PALAVRAS-CHAVE: Direito de Família; Código Napoleônico; Constituição Italiana.
\end{abstract}

ABSTRACT: This article presents an analysis of the treatment received by families and children throughout the Italian Constitution, describing the slow evolution of the family law area in the last 200 years. Firstly, Family Law was understood to be attached to the Canon Law. However, with the separation of Church and State, family law became a part of the civil regulated environment, highly influenced by The Napoleonic Code. The 1942 Italian Civil Code marks a period of absolute domain of State over family using this institution as basis for a Fascist Regime. Such period had a more traditional view of family, where the father was a central authority figure and the children born under a legal marriage were viewed differently from the ones conceived in an extra-marital relationship. Only in recent times, with a new Italian Constitution, the family began to be perceived with another set of values, providing equal rights to every child born, independently of the marital relationships involved. Within this cultural and legislative evolution, the text continues its account of the new treatment received by italian families.

KEYWORDS: Family Law; Napoleonic Code; Italian Constitution.

Artigo recebido em 02.08.2012. Artigo aceito para publicação em 13.08.2012 mediante convite.

${ }^{1}$ La Famiglia e i Figli nella Costituzione, in I Diritti Costituzionali (a cura di) R. Nania e P. Ridola, Torino 2001. Traduzido do italiano por Débora Minuzzi, Mestranda em Direito pela Pontifícia Universidade Católica do Rio Grande do Sul. debora.minuzzi@acad.pucrs.br

${ }^{2}$ Catedrática de Direito Constitucional da Universidade de Urbino. 
SUMÁRIO: 1. Contexto Histórico: A História do Ordenamento Familiar do Código Napoleônico ao Código Civil Italiano de 1942; 2. Os Princípios Constitucionais do Direito de Família: As Inovações do Constituinte, A Lenta e Difícil Atuação Legislativa, O Papel do Direito Constitucional; 3. A Família como Sociedade Natural; 4. A "família legítima" e a "família de fato": Significado e Limites do Favor Legitimitatis Sancionado pelo Artigo 29, parágrafo $1^{\circ}$, da Constituição; 5. A Igualdade Moral e Jurídica dos Cônjuges e a Unidade da Família; 6. A Posição Constitucional dos Filhos na Família: Filhos Legítimos e Filhos Naturais; 7. A Família na Dimensão Europeia; Referências Bibliográficas.

SUMMARY: 1. Historical Context: The History of the Family Structure Within the Napoleonic Code and the 1942 Italian Civil Code; 2. The Family Law Constitutional Principles: The Inovation of the Constituent, The Slow and Difficult Legislative Action, The Role of the Consitutional Law; 3. The Family as a Natural Society; 4. The "legitimate family" and the "non marital family": Meanings and Limits of Favor Legitimitatis Sanctioned by the Article 29, $1^{\circ}$ paragraph, of the Constitution. 5. The Moral and Juridic Equality of Husband and Wife and the Family Unity; 6. The Constitutional Position of Children in a Family: Legitimate and Illegitimate Childs; 7. The Family in the European View; Bibliographic References.

\section{CONTEXTO HISTÓRICO: A HISTÓRIA DO ORDENAMENTO FAMILIAR DO CÓDIGO NAPOLEÔNICO AO CÓDIGO CIVIL ITALIANO DE 1942}

O direito de família representa, hoje, um setor do ordenamento jurídico do Estado e está disciplinado na Carta Constitucional, no livro primeiro do Código Civil, profundamente reformado em 1975, bem como por várias leis especiais (adoção, divórcio, etc).

Mas não foi sempre assim. De fato, foi somente após a afirmação dos princípios da Revolução Francesa que se abriu caminho para a ideia de um direito de família regulado pelo ordenamento estatal e, sucessivamente, com o Código Napoleônico de 1804, a competência do Estado como responsável pelo direito de família recebe harmônica e definitiva consagração.

Até então, a disciplina jurídica do casamento e dos atos do estado civil não cabia ao Estado, sendo reservada ao Poder Eclesiástico. ${ }^{3}$

No antigo regime, o catolicismo era a única religião legal e em parte se confundia com a instituição estatal. Os ministros do culto católico tinham, assim, um papel exclusivo na atividade de redação de todos os atos do estado civil, além de naturalmente celebrarem o casamento, disciplinado pelo direito canônico.

Esse monopólio acaba no momento em que foi afirmada a liberdade do culto (com um Edito de 1787 - pouco antes da Revolução - na França reconhecia-se o estado civil dos protestantes que não foram mais obrigados a recorrer aos ministros católicos para a celebração dos seus casamentos) de onde segue a necessidade de excluir a intervenção da autoridade religiosa no âmbito civil. A Assembléia Constituinte francesa declarou que o Poder Legislativo teria estabelecido para todos os cidadãos, sem distinção, o modo de celebrar os casamentos, constatar os nascimentos e as mortes, e que o

\footnotetext{
${ }^{3}$ UNGARI, Paolo. Storia del Diritto di Famiglia in Italia. Bologna, 1974.
} 
Estado designaria os oficiais públicos destinados a receber e cuidar os relativos atos; declaração que inserida na Constituição de 1791 equivaleu a proclamar o princípio da secularização. O direito do Estado se apropria, assim, de uma série de relações que precedentemente haviam sido reguladas somente pela religião e, portanto, pelo ordenamento canônico.

Ao modelo de família disciplinado pelo Código Napoleônico (ao qual cabe fazer um breve aceno não só porque teve vasta aplicação na Europa Continental e influenciou em grande parte o Código Civil italiano unitário de 1865, mas também porque a própria organização jurídica atual da família encontra suas raízes nesse texto, cuja influência é ainda hoje visível, sobretudo, no sistema legislativo - basta pensar, como por exemplo no divórcio consensual -) é delegada a tutela do núcleo legítimo, ordenado hierarquicamente e posto sob a autoridade do chefe de família.

Por um lado é rigidamente regulada a necessária relação de antecedência entre rito civil e (eventual) rito religioso - aliás, a proibição do casamento religioso antes do civil foi em seguida sancionada pelo Código Penal de 1810 -. Por outro lado, mostra a condição de total submissão da mulher, particularmente evidenciada nas disposições relativas à, assim chamada, autorização marital.

Sem autorização do marido, a mulher não podia estar em juízo. Ainda que em comunhão de bens não podia doar, alienar ou adquirir a título gratuito ou a título oneroso sem que o marido participasse do ato ou manifestasse 0 seu consentimento por escrito.

Assim, também, o faz o legislador italiano de 1865, após a unificação da Itália, delineando um modelo de família autoritário, fundamentado na figura do marido (pai) e, portanto, mostrando uma nítida disparidade de condições entre homens e mulheres; um modelo, além disso, que mais correspondia à tradicional família italiana da pequena e média burguesia e da sociedade rural.

Reencontra-se, desse modo, autorização marital, requerida para o cumprimento de todos os atos patrimoniais de alguma relevância - doações, alienações de bens imóveis, etc -, assim como para estar em juízo (instituto, esse, abolido somente com a Lei $n^{\circ} 1.176 / 1919$, que certamente deve ser relacionado com o papel social que a mulher desempenhou durante a Primeira Guerra Mundial). A "autoridade dos pais", ainda que dissessem respeito a ambos os cônjuges, era exercida pelo pai; não eram admitidos questionamentos sobre paternidade senão nos casos excepcionais.

Em relação ao regime do vínculo, o Código Unitário reintroduz no ordenamento italiano o casamento civil (reintroduz porque, na realidade, o casamento civil, previsto no Código Napoleônico, que havia sido aplicado em grande parte no território italiano, foi, depois, revogado pelos códigos anteriores à unificação, que sofreram fortemente o clima da restauração italiana), afirmando, desse modo, o princípio da clara separação entre Estado e Igreja e da liberdade entre ambos. Por outro lado, no que diz respeito 
à relação entre casamento civil e casamento religioso, diferentemente do francês, como já dito, que vetava a realização do casamento religioso antes do civil, para o legislador italiano era indiferente que a celebração do rito religioso acontecesse antes ou depois que a do civil.

Até o acordo entre o Estado e a Igreja em 11 de fevereiro de 1929 (que marca a profunda divisão entre o Estado italiano e a Santa Sé, após a unificação da Itália, também em $1870 \mathrm{com}$ a tomada de Roma) o ordenamento italiano, portanto, conhecia só o casamento civil, cujo ato era celebrado segundo o rito civil.

Foi com o acordo que se introduziu a figura do casamento concordatário, celebrado segundo o rito disciplinado pelo direito canônico, para o qual são reconhecidos efeitos civis por parte do Estado italiano, pela transcrição do casamento nos registros do estado civil.

Também o regime da relação do casamento concordatário é delegado pelo Estado à jurisdição dos tribunais e ministérios eclesiásticos, para tudo aquilo que se refere às causas de nulidade, devendo o Estado limitar-se a executar os provimentos deferidos pelos juízos eclesiásticos com pedido emitido pela Câmera de Conselho da Corte de Apelação Competente (a chamada deliberação). Na prática, o Estado italiano havia renunciado à própria soberania nesta matéria, em favor do ordenamento canônico.

A introdução do instituto do divórcio (com a Lei no 898/1970), aplicável também aos casamentos concordatários, e a sentença da Corte Constitucional $n^{\circ} 18 / 1982$ inovaram profundamente a disciplina da relação do casamento concordatário, recuperando amplas margens de soberania para o ordenamento estatal.

No Código Civil de 1942, há uma visão arcaica da família, marcada por uma profunda desigualdade entre os cônjuges ou, melhor, há um verdadeiro comando do marido na qualidade de chefe da família (à mulher não é permitido trabalhar fora de casa sem o consentimento do marido ou, corresponder-se com outras pessoas, não podendo, na prática, ter uma vida social). Acrescenta-se a isso, a concepção autoritária do regime fascista, que acentua a contraposição entre a instituição familiar, cujo interesse é considerado prioritário em relação aos interesses particulares e individuais de cada membro da família.

Mesmo não tendo adquirido a condição de pessoa jurídica, acentua-se fortemente a visão da família como instituição, estrutura basilar da nação, útil para a realização da política demográfica do regime e, portanto, destinada a obedecer a um regime jurídico cada vez menos privado e autônomo, mas também mais público, subordinado às supremas exigências do Estado e da nação.

Está é a mudança do código que explica e justifica numerosas disposições: da indissolubilidade do casamento ao poder do marido, do poder da pátria até a condição dos filhos naturais.

Inútil enfatizar que a lei foi sempre nitidamente favorável à família legítima, isto é, aquela fundada no casamento. 


\section{OS PRINCÍPIOS CONSTITUCIONAIS DO DIREITO DE FAMÍLIA: AS INOVAÇÕES DO CONSTITUINTE, A LENTA E DIFÍCIL ATUAÇÃO LEGISLATIVA, O PAPEL DO DIREITO CONSTITUCIONAL}

Os princípios fundamentais e inovadores, introduzidos pela Constituição Republicana, refletem-se significativamente na disciplina jurídica da família que, concebida como "sociedade natural fundada no casamento" (art. 29, parágrafo $1^{\circ}$, da Constituição Federal), distancia-se profundamente da concepção proposta poucos anos antes pelo Código Civil.

Observemos já, a propósito, que na perspectiva de investigação, que interessa ser discutida aqui, o direito de família é aquele típico da ciência do direito constitucional. O que propomos, em outros termos, é mostrar quais orientações nas quais se funda a nossa Carta Constitucional, consciente, antes de tudo, de que se trata de um tema no qual se entrelaçam profundamente (em posição frequentemente antitética) hábitos mentais tradicionais, paixões civis, sentimento religioso, convicções políticas, todos, indistintamente, levados a instrumentalizar a interpretação de um dado jurídico.

É dever do jurista a difícil tarefa de colocar-se em uma posição totalmente imparcial, imune a escolhas ideológicas apriorísticas, e valendo-se dessa posição, identificar as escolhas e os valores que a Constituição da comunidade estatal efetivamente estabeleceu.

Ao fazê-la, todavia, é necessário observar, com base nos dispositivos constitucionais, que nem sempre será possível identificar as escolhas e os valores da comunidade estatal, mesmo recorrendo a uma interpretação sistemática, ou seja, uma unívoca mens legis.

Os perfis constitucionais do direito de família, em outros termos, ainda que identificáveis, nem sempre são definíveis na plenitude de seus contornos. Isso porque se trata de um dos campos em que majoritariamente a Assembléia Constituinte determinou o contraste e, portanto, o compromisso entre as forças laicas e as forças católicas com uma consequente ambiguidade das fórmulas legislativas constitucionais.

Essa circunstância não deixa dúvida de que o ponto de partida é o pluralismo jurídico que o artigo $2^{\circ}$ da Constituição põe na base do nosso ordenamento constitucional, superando a contraposição entre visão individualista e visão social da posição política e das relações jurídicas. O princípio de defesa das liberdades fundamentais da pessoa-indivíduo une-se ao princípio do pluralismo, entendido como garantia da livre existência dos grupos sociais, organizados onde melhor se possa desenvolver a personalidade de cada pessoa. ${ }^{4}$

Esse princípio impõe o respeito de todas as formações sociais de que faz parte a pessoa, seja o fruto de uma livre-iniciativa ou adesão de cada indivíduo que participa daquele grupo, sejam aquelas institucionalizadas

\footnotetext{
${ }^{4}$ AMATO, Giuliano; BARBERA, Augusto. Manuale di Diritto Pubblico. Bologna, 2001.
} 
nas quais estamos necessariamente inseridos. A família, antes de tudo, é a formação social que no nosso ordenamento assume relevância constitucional; fundamental é o papel que esta desempenha, quer para o indivíduo, quer para a sociedade no seu todo.

A constituição introduz, assim, normas radicalmente novas em relação ao passado, interpretando a família como sociedade natural, fundada no casamento e na igualdade moral e jurídica dos cônjuges, devendo defender os filhos legítimos, sem deixar de tutelar juridicamente e socialmente os filhos naturais (arts. 29, 30 e 31 da Constituição).

Apesar disso, é também fácil notar como, por determinados aspectos, a Constituição volta a apanhar com a mão esquerda aquilo que deu com a mão direita. Assim, "o casamento é ordenado sobre a igualdade moral e jurídica dos cônjuges", mas "com os limites estabelecidos pela lei com o fim de garantir a unidade familiar" (artigo 29, parágrafo $2^{\circ}$, da Constituição); "a lei assegura aos filhos nascidos fora do casamento qualquer tutela jurídica e social", mas "compatível com os direitos dos membros da família legítima" (artigo 30, parágrafo $3^{\circ}$, da Constituição); "a lei dá as normas", bem como "os limites para a procura da paternidade" (artigo 30, parágrafo $4^{\circ}$, da Constituição).

É, ao mesmo tempo, relevante o fato de utilizar-se uma linguagem genérica no parágrafo $1^{\circ}$, artigo 29 da Constituição. "A república reconhece os direitos da família como sociedade natural fundada no casamento", ainda que represente um princípio fundamental da disciplina constitucional da família e da sua relação com o Estado.

Mas o que deve ser entendido por direito de família e pela própria família como sociedade natural, quando na história e mesmo na sociedade contemporânea existem tantos modos diversos para entender tais expressões?

Não por acaso, essas fórmulas, como veremos, obtiveram diversas interpretações de acordo com a concepção ideal, religiosa ou filosófica do intérprete.

Em síntese, se alguns perfis da disciplina constitucional parecem profundamente inovadores e nitidamente definíveis, outros são muito menos. Isso, pela ampla margem de discricionariedade deixada pelo legislador comum ou, ainda, porque, mesmo sendo definíveis, acabam parecendo nada inovativos se confrontados com as novas instâncias da sociedade civil.

Por outro lado, a relevância jurídica e a real inovação trazida pelos princípios constitucionais corria o risco de ser fortemente redimensionada pela normativa então vigente, marcadamente contida no Código Civil de 1942, fundada como se viu em um modelo de família diferente.

Uma adequação do ordenamento jurídico italiano aos novos princípios constitucionais requereu anos, décadas de um processo lento e cansativo, fruto de uma fusão e orientações legislativas no ordenamento jurídico, as quais se ligam, evidentemente, a um sofrido e complexo acontecimento social e de costume. 
No fundo, somente vinte e sete anos depois da entrada em vigor da Constituição de 1975, que, com a reforma do direito de família, se dá plena atuação às normas constitucionais, inspiradas na igualdade sem distinção de sexo entre todos os cidadãos e na liberdade e dignidade entre ambos os cônjuges, no lugar do patriarcado que até então havia dominado os costumes e as relações familiares.

Esperando a reforma, está o direito da Corte Constitucional que, mesmo com oscilações e com uma contínua mudança de orientações, fornece as contribuições mais importantes, seja eliminando aos poucos do ordenamento as disposições do Código Civil em claro contraste com as prescrições constitucionais, seja solicitando e estimulando o legislador a introduzir uma nova disciplina do instituto familiar conforme os princípios constitucionais e os diversos costumes sociais e clima político, hoje, difundidos no país.

Uma obra de contínua aplicação dos princípios constitucionais que inicia com as históricas sentenças sobre o adultério (de fato, se com uma primeira sentença, n 64/1961, a Corte rejeita a exceção de inconstitucionalidade do artigo $559 \mathrm{CP}$, que sancionava penalmente somente a infidelidade da mulher, poucos anos depois, com duas sucessivas pronúncias - Sentenças $n^{\circ s} 126$ e 127/1968 - a Corte declara a ilegitimidade constitucional da discriminação entre a infidelidade do marido e aquela da mulher estabelecida pela norma penal, cancelando na mesma data, também, o diferente tratamento civil do adultério) e prossegue exaustivamente afirmando a igualdade moral e jurídica dos cônjuges (assim, por exemplo, no que diz respeito às relações patrimoniais entre os cônjuges, a Corte, privilegiando uma nova concepção de casamento, faz cair a antiga proibição de doação entre cônjuges - Sentença no 91/1973 - ou, ainda, chamada a enfrentar a questão da cidadania da mulher com a Sentença $n^{\circ} 87 / 1975$, declara ilegítima a previsão legislativa do artigo 10 da Lei $n^{\circ}$ 555/1912, que estabelecia a perda da cidadania, independentemente de uma declaração de vontade da mulher italiana que tivesse contrato de casamento com um estrangeiro).

Certamente mais cautelosa em relação à responsabilidade do pai sobre os filhos menores, a Corte nem ao menos vislumbrou que isso pudesse se opor ao princípio constitucional da igualdade entre os cônjuges (Sentença $n^{\circ} 102 / 1967$ e 128/1970). Aliás, a Sentença $n^{\circ} 71 / 1966$ chegou afirmar que só o pai poderia exercitar a tutela dos filhos naturais, reconhecidos também pela mãe, mesmo que nesse caso não houvesse aquelas razões de "unidade da família" que haviam motivado os juízos constitucionais a reconhecer a primazia da vontade do pai.

Um direito que, ao fazer o controle de legitimidade, oferece a imagem de um amplo processo de transformação do ordenamento. Os progressos na direção de igualdade entre os cônjuges, porém, ainda se chocavam contra as disposições que, de acordo com o caso, "tendiam a impor à mulher o sobrenome, a residência e a cidadania do marido, assegurando ao varão os 
poderes de governo e de administração, sem descrição dos bens da mulher e reservavam, de qualquer maneira, o exercício da tutela dos menores apenas ao pai, legitimado há outras e numerosas formas de dominações da personalidade materna". ${ }^{5}$

A desejada reforma do direito de família chega, portanto, com a Lei de 19 de maio de 1975, n 151, que codifica a igualdade moral e jurídica dos cônjuges como regra de vida entre eles e na relação com os filhos. São, assim, finalmente abolidas ou modificadas todas as normas que, na precedente normativa, afirmavam a supremacia do marido na relação conjugal (do poder do marido sobre a mulher aos recíprocos direitos e deveres do marido e da mulher, a obrigação da mulher de assumir o sobrenome do marido e de segui-lo na residência que ele tivesse escolhido para viver, etc.), assim como é abolida a tutela exclusiva do pai sobre o filho, sendo substituída pela tutela de comum acordo, ou seja, por ambos os genitores.

Ainda, em relação aos filhos, a nova lei conferiu igualdade moral e jurídica aos filhos legítimos e naturais (excluído os incestuosos).

No plano das relações econômicas entre os cônjuges, a lei da reforma introduziu, como regime patrimonial comum, em falta de uma diferente escolha, a comunhão dos ganhos e dos bens adquiridos durante o casamento, regime que a própria Corte quis estabelecer (Sentença $n^{\circ}$ 187/1974) com o objetivo de valorização do trabalho doméstico da mulher, totalmente negligenciado na precedente disciplina.

É prevista a intervenção do juiz, requerida por um dos cônjuges, sem necessidade de particulares formalidades, em caso de desacordo, quer nas relações pessoais e patrimoniais quer nas relações entre eles e os filhos.

A reforma do direito de família havia sido precedida pela introdução do divórcio com a Lei de $1^{\circ}$ de dezembro de 1970, nº 898 (mas dessa falaremos na sequência), e foi seguida por muitas outras leis, mesmo que não dissessem respeito à família, acabaram por incidir diretamente na matéria e, por isso, é oportuno que se fale brevemente: a Lei $n^{\circ} 194 / 1978$, que trata da tutela social da maternidade e da interrupção voluntária da gravidez, que tirou da clandestinidade a prática do aborto, regulamentando-o (lei submetida a referendo popular em 1981, que confirmou a escolha do legislador); a Lei $\mathrm{n}^{\circ} 405 / 1975$, que instituiu o serviço de assistência à família e à maternidade (os consultores familiares); a Lei $n^{\circ} 114 / 1977$, sobre posição fiscal da mulher casada, que superou o princípio de "acúmulo" de renda; a Lei no 903/1977 e a Lei no 125/1991, que, ao tutelar a "igualdade" da mulher trabalhadora, tende a eliminar a discriminação que a mulher pode sofrer pelo estado de família; a Lei $n^{\circ} 123 / 1983$, relativa à aquisição da cidadania também por vínculo de casamento de um estrangeiro com uma cidadã italiana.

${ }^{5}$ BESSONE, Mario. Commento agli Articoli 29, 30 e 31 Costituzione. In. Commentario della Costituzione, a cura di Giuseppe Branca. Bologna, 1976. 


\section{A FAMÍLIA COMO SOCIEDADE NATURAL}

Como se observou anteriormente, a fórmula, "a república ter reconhecido os direitos da família como sociedade natural fundada no casamento", representou o fruto do compromisso a que chegou a Assembléia Constituinte entre as duas diferentes concepções - católica e laica - da relação entre família e ordenamento.

Assim, enquanto os católicos desejavam garantir o reconhecimento da parte pelo ordenamento constitucional do Estado, de uma realidade pré-jurídica, com seus direitos próprios e inalienáveis (inteiramente subtraída da ingerência estatal na visão mais integralista; dotada de uma ampla garantia de autonomia, mas, sem, por isso, excluir uma possível intervenção do direito positivo na visão católica moderada), a doutrina laica apunha-se radicalmente à imposição constitucional de um determinado modelo de família - o católico - que não dava conta da complexidade social e da variabilidade histórica dos modelos de convivência familiar.

É importante lembrar que, na concepção laica tradicional, deixada às margens de uma visão libertária e contratual, a família é concebida como comunidade reconhecida e inteiramente disciplinada no ordenamento pelo Estado, mas dotada de autonomia relevante sob o ponto de vista constitucional e que tolera, somente até certo ponto, intervenções externas de trabalho pela legislação do Estado ou pela atividade dos seus juízes.

Portanto, superando a contraposição entre tese jus naturalista (que concebe a família como titular de um jus natural e de uma soberania, independentemente do reconhecimento estatal) e normativa (que configura a autonomia reconhecida à família derivada de normas que não seriam diferentes daquelas que competem às formações sociais, conforme 0 artigo $2^{\circ}$ da Constituição, ou seja, em relação a outras formas de autonomia que o texto constitucional reconhece), uma leitura correta do dispositivo constitucional parece significar simplesmente a prioridade da família em relação à organização da sociedade no Estado segundo o direito. $\mathrm{O}$ uso do termo "natural" exprime a ideia de que a família é tutelada pela Constituição, na sua acepção de imprescindível e essencial exigência da vida do homem, lugar onde se desenvolve a sua personalidade. ${ }^{6}$

O reconhecimento dos direitos de família como "sociedade natural", além disso, significa o estabelecimento de limites intransponíveis à ação estatal, que não pode desconhecer com a sua legislação a existência de um grupo específico intermediário entre o indivíduo e o Estado, "natural" da organização social que, como tal, deve ser protegido.

No entanto, outro aspecto da questão deve ser esclarecido. O reconhecimento dos "direitos de família" fez surgir na doutrina a questão

\footnotetext{
${ }^{6}$ RESCIGNO, Pietro. La Tutela dei Figli Nati fuori del Matrimonio. Riv. dir. matr., 1965; Persona e Comunità. Bologna, 1966; Riforma del Diritto di Famiglia. Padova, 1972; Manuale del Diritto Privato Italiano. Napoli, 1996.
} 
relativa ao tipo de figura jurídica que a atribuição dos direitos em questão implica; em particular, foi teorizada a possibilidade de identificar um conjunto de direitos que dizem respeito à família quanto sujeito autônomo, em relação aos membros que a compõem. ${ }^{7}$

Ora, partindo da premissa que geralmente a teorização de interesses que se referem ao grupo, concebido como sujeito distinguido por cada um que o compõe, implica ideologias objetivamente autoritárias porque, como foi observado, ${ }^{8}$ a prospecção de um genérico e indefinido interesse superior tende a legitimar a arbitrária violação da personalidade de cada membro da família. É necessário, além disso, observar que o recurso à figura da entidade coletiva não deve ser funcional em relação à tutela do interesse de cada pessoa; em outros termos, é desejável tal tutela somente, caso não seja possível tutelar diretamente um interesse referente a um indivíduo em particular.

Ao contrário, a disposição em exame exprime uma síntese verbal, "a família", que se refere aos direitos de cada um no âmbito familiar, carecendo de traços característicos que determinam a relevância da atividade do grupo; os "direitos de família", em outros termos, assumem relevância nas relações recíprocas entre os familiares enquanto pressupõe o pertencimento à família, mas não a presença de um indivíduo como referência.

Deve-se excluir, seguindo-se a doutrina majoritária, que a instituição familiar possa ser titular de um interesse separado e autônomo, superior em relação àquele do livre desenvolvimento das pessoas. ${ }^{9}$

Assim, o caráter de "sociedade natural" da família e a prioridade em relação à comunidade estatal, na perspectiva de uma reconstrução que responda a uma leitura conforme ao nosso direito positivo, deve ser entendido no sentido de que, se é negada à família a dimensão do fenômeno puramente "jurídico" - respeitando a sua autonomia e o interesse de cada um em ordenar no modo original e livre as suas relações de família contra as tentações autoritárias de intervenções externas - ao mesmo tempo, todavia, exclui-se radicalmente que a disciplina do grupo familiar possa ser colocada em ordenamentos fora do Estado, sendo esses radicados na religião, nos costumes ou nas particulares tradições de lugares ou de grupos.

\footnotetext{
7 BARILE, Paolo. II Soggetto Privato nella Costituzione Italiana. Padova, 1953; Eguaglianza dei Coniugi ed unità della Famiglia. In. Scritti Giuridici in Memoria di Vittorio Emanuele Orlando. Padova, 1957; L`eguaglianza dei Coniugi nella Giurisprudenza Costituzionale. In Diritto e Ocietà, 1974; Diritti dell uomo e Libertà Fondamentali. Bologna, 1988; GRASSETTI, Cesare. I Principi Costituzionali Relativi al Diritto di Famiglia. In. Commentario Piero Calamandrei. Roma, 1949.

${ }^{8}$ BESSONE, Mario. Commento agli Articoli 29, 30 e 31 Costituzione...

9 RESCIGNO, Pietro. La Tutela dei figli nati fuori del Matrimonio...; Persona e Comunità...; Riforma del Diritto di Famiglia...; Manuale del Diritto...; PERLINGIERI, Pietro. Commento alla Costituzione Italiana. Napoli, 1997.
} 


\section{A "FAMÍLIA LEGÍTIMA" E A "FAMÍLIA DE FATO": SIGNIFICADO E LIMITES DO FAVOR LEGITIMITATIS SANCIONADO PELO ARTIGO 29, PARÁGRAFO $1^{\circ}$, DA CONSTITUIÇÃO}

A família, para a qual são reconhecidos os direitos próprios de uma "sociedade natural", como se tentou esclarecer anteriormente, é a família "fundada no casamento", quer seja no casamento civil quer seja no casamento concordatário.

Somente esta configuração de família representa para o legislador a família legítima.

Mas a garantia formulada nesses termos não denota que a "família de fato" ou natural, isto é, aquela não fundada no casamento, mas que nasce da convivência more uxório, seja completamente irrelevante.

Posto que, em substância, a família de fato apresente o mesmo conteúdo da convivência que tem origem no casamento (entre os sujeitos que vivem como cônjuges se estabelecem análogos vínculos de fidelidade, coabitação, assistência e recíproca contribuição aos ônus patrimoniais), nem ao menos se pode contestar que ela receba uma, ainda que limitada, relevância constitucional: o artigo 30 da Constituição reconhece aos pais o direito de educar os filhos, embora nascidos fora do casamento, e impõe ao legislador assegurar a eles "qualquer tutela compatível com os direitos da família legítima". O artigo 31 da Constituição, além disso, impõe ao Estado a proteção da maternidade, da infância e da juventude não a diferenciando, sob esse ponto de vista, da família de fato.

As normas que oferecem garantias aos direitos fundamentais da pessoa, mediante providências concedidas às famílias (artigo 34 , parágrafo $4^{\circ} \mathrm{e}$ artigo 36 da Constituição), não são limitadas à família legítima, devendo se aplicar também às relações de convivência e, em particular, às relações entre pais e filhos, mesmo que estabelecidas fora do casamento.

Essa permissão, que faz referência o texto constitucional sobre o fundamento da família no casamento, impõe ao intérprete ao menos duas ordens de questões ligadas, quer ao papel que efetivamente quis se dar ao casamento - isso evidentemente em relação à tutela constitucional da família de fato -, quer se a escolha do constituinte implica também uma determinada opção em relação à existência ou não de um princípio de indissolubilidade de vínculo.

A identificação do fundamento da família no casamento colocou na doutrina o problema relativo à compatibilidade entre o artigo em questão e a norma que introduziu o divórcio no ordenamento italiano (Lei $n^{\circ}$ 898/1970 modificada pela Lei $n^{\circ} 436 / 1978$ e, sucessivamente, pela Lei $n^{\circ} 74 / 1987$ ).

A respeito disso, é necessário, porém, enfatizar que a questão deve ser corretamente posta, tendo presente que, na Itália, como já foi dito, não existe um só tipo de casamento válido para o ordenamento estatal, mas diversos tipos e que, consequentemente, a legitimidade constitucional do divórcio deve 
ser avaliada em relação a cada fattispecie; quer seja em relação ao casamento civil (mas também ao casamento celebrado perante o ministro de culto, admitindo-se que se equivale ao casamento civil), quer seja em relação ao casamento concordatário.

Quanto ao casamento civil, os partidários da indissolubilidade do vínculo conjugal afirmaram que o reconhecimento constitucional da família como "sociedade natural fundada no casamento", assim como os seus direitos particulares derivados de uma preexistência em relação ao ordenamento estatal, significa considerar a realidade da família como se apresentou na história, na tradição e no costume da sociedade italiana.

A indissolubilidade do casamento, em suma, seria evidenciada no disposto constitucional como parte integrante do instituto familiar formado na nossa realidade histórico-social.

Mas a fórmula utilizada pelo legislador tem um viés jus naturalístico que prescinde de uma particular qualificação histórica e, no entanto, apresenta uma amplitude de significados dos quais aquele proposto é somente um entre os tantos e, por isso, incapaz de fornecer uma interpretação unívoca. ${ }^{10}$ Além disso, já constatamos (na parte 3 ) que o reconhecimento dos direitos da família como sociedade natural significa colocar um limite na ação do Estado que não pode desconhecer, com a sua legislação, a existência desses direitos como produto natural da organização social. Isto não comporta, de maneira alguma, uma tomada de posição sobre o tema específico da indissolubilidade ou não do vínculo conjugal. A fórmula adotada, em outros termos, não assume algum valor qualificativo no sentido da legitimidade ou ilegitimidade do divórcio.

Enfim, acrescenta-se que, se na Assembléia Constituinte foi rejeitado o disposto que explicitamente previa a indissolubilidade do vínculo, é necessário concluir, interpretando o artigo 29 da Constituição, que este não impõe nenhuma proibição constitucional à instituição do divórcio no nosso ordenamento.

Isso evidentemente em relação ao casamento civil, já que deve ser desenvolvida uma ordem de considerações diferente e mais complexa para o casamento concordatário.

Nesse ponto, é necessário esclarecer se é ou não evocável a existência de um impedimento derivante da disposição do artigo $7^{\circ}$ da Constituição.

Sustentou-se que o legislador, mediante o artigo $7^{\circ}$ da Constituição, entendeu constitucionalizar o pacto (entre a Igreja e a Itália), e tal ato conferiu ao seu conteúdo força de lei constitucional, ou, pelo menos, constitucionalizou o princípio concordatário, isto é, a exigência de que as modificações nos pactos ocorram de comum acordo entre as duas partes; disso se argumentou que o reconhecimento efetuado - nos termos do art. 34 do acordo - dos efeitos civis do casamento de direito canônico, devidamente transcrito, implica

${ }^{10}$ SPAGNA MUSSO, Enrico. Diritto Costituzionale. Padova, 1992. 
a inadmissibilidade de modificações unilaterais, sob pena de violação do disposto constitucional.

Ora, é perfeitamente sustentável que a anulação dos efeitos civis que o Estado italiano se empenha em reconhecer no casamento de direito canônico, sem que isso comporte a consagração do instituto do direito canônico como instituto próprio, não determina uma modificação unilateral do acordo.

O Estado italiano empenhou-se em reconhecer os efeitos civis, mas não renunciou às determinações do seu conteúdo, conservando a disponibilidade no âmbito do próprio ordenamento.

A introdução do divórcio pela lei ordinária deve ser, portanto, considerada constitucionalmente legítima também em relação ao casamento concordatário, o qual, se fosse eventualmente anulada a transcrição nos registros do estado civil, continuaria mantendo a originária e inalterada validade do direito canônico.

A mesma Corte Constitucional, a qual se recorreu muitas vezes para confirmar a compatibilidade entre a legislação ordinária (que prevê a dissolução do casamento civil e a cessação dos efeitos civis do casamento concordatário com o artigo 29 da Constituição), rejeitou as várias exceções de ilegitimidade constitucional, excluindo, entre outros e em particular, que a reserva dos juízos de nulidade (que é sempre originária) dos casamentos concordatários aos Tribunais Eclesiásticos compreende também os juízos de dissolução sucessiva (sentença no 169/1971, 176/1973, 181/1976 e, por último, 18/1982).

Mas o segundo modo de análise de que se falou anteriormente diz respeito especificamente ao significado que o legislador quis atribuir ao favor legitimitatis, em relação à tutela constitucional da família de fato.

Para a doutrina mais intransigente, a referência ao casamento adquire um valor absoluto de defesa da instituição matrimonial. Uma leitura do artigo 29 da Constituição, que repousa no pressuposto da exclusividade de referência à família legítima - a tutela constitucional refere-se não estritamente à sociedade natural, mas somente à sociedade natural fundada no casamento e a presumida inadequação de uma referência genérica ao artigo $2^{\circ}$ da Constituição leva a excluir qualquer forma de tutela das uniões livres; as convivências de fato seriam irrelevantes juridicamente. ${ }^{11}$

Diferentemente, a orientação prevalecente, ainda que reconheça uma situação constitucional de privilégio para a família legítima, considera, ao mesmo tempo, absolutamente não eliminável a tutela proporcionada às convivências more uxorio do artigo $2^{\circ}$ da Constituição, quais sejam: formações sociais abstratamente idôneas a desempenhar a função de lugar de afetos para o desenvolvimento e a tutela do valor da pessoa. ${ }^{12}$

\footnotetext{
${ }^{11}$ GRASSETTI, Cesare. I Principi Costituzionali Relativi al Diritto di Famiglia...; GIORGIANNI, Michele. Problemi Attuali di Diritto Familiar. In. Studi in Memoria di Filippo Vassalli. Torino, 1960.

${ }^{12}$ BESSONE, Mario. Commento agli Articoli 29, 30 e 31 Costituzione...
} 
O artigo 29 da Constituição, mesmo considerando o casamento elemento de distinção da família legítima para a qual se reserva uma posição favorável em relação à família de fato, ao mesmo tempo, não impede alguma forma de reconhecimento e de tutela jurídica para essa última que, por outro lado, nos parece, que é até mesmo imposta por outras normas constitucionais e, em particular pelo artigo $2^{\circ}$ da Constituição.

A Constituição, em outras palavras, não autorizaria a exclusão das convivências de fato do grupo das formações sociais expressamente tuteladas no artigo $2^{\circ}$ da Constituição, seja na ausência da prole - porque, em princípio, não se pode excluir das convivências de fato o desenvolvimento de valores de ordem espiritual e garantias de estabilidade que representam uma formação social digna de tutela -, seja quando a livre união dos pais assegura o cumprimento das funções de sustento, instrução e educação da prole.

Também na família de fato, portanto, quando essa assume as formas de um núcleo estável, de uma convivência que continua no tempo e funcionalmente análoga a uma família legal, é possível identificar os traços de uma formação social dentro da qual os indivíduos experienciam importantes trocas afetivas e, desenvolvem a sua personalidade e amadurecem; para essa formação o ordenamento não pode negar um nível mínimo de proteção jurídica.

Por outro lado, se no plano sociológico as uniões de fato representam um fenômeno que se manifesta em muitas situações diferentes a que concorrem causas muito variadas (que determinam e qualificam as práticas de convivência e de geração fora do casamento), no plano jurídico o problema consiste em estabilizar qual deve ser o nível de proteção jurídica e, consequentemente, com quais conteúdos.

É necessário estabelecer quais os aspectos de uma relação existente na origem de uma situação não legal estão sujeitos a regras legais e, evidentemente, esclarecer quais são essas regras.

E, ao fazê-lo, é importante distinguir as regras de que resulta a relevância jurídica da família de fato, levando-se em consideração, se dizem respeito a um ou a outro dos dois lados que o fenômeno envolve diretamente; de um lado, o tema de mais relevância é o da tutela dos filhos nascidos fora do casamento, aspecto concernente às consequências jurídicas da filiação natural, de outro, o perfil que diz respeito às relações entre os conviventes (prevalentemente de natureza patrimonial), independentemente da circunstância de terem ou não gerado filhos.

Avaliações de política legislativa impõem a procura de um difícil e delicado equilíbrio entre o devido respeito da liberdade individual e a necessária intervenção da lei e das instituições públicas na defesa dos sujeitos mais fracos da relação.

A decisão de refutar o vínculo jurídico e de subtrair as próprias relações familiares no domínio da lei pode expressar uma reivindicação de liberdade 
e de autonomia, na tentativa de uma mais autêntica espontaneidade dos sentimentos que um Estado e um legislador laico não podem desrespeitar. Mas, neste ponto, é necessário evitar que a reivindicação da liberdade dos afetos do vínculo burocrático da lei e a consequente ausência das garantias formais que tutelam a condição dos membros da família legítima se transformem em uma reivindicação de liberdade em sentido único. De uma liberdade que se exerce causando danos aos sujeitos mais fracos da relação (geralmente a mulher e, sobretudo, os filhos), transformando-se em uma fuga dos empenhos e das responsabilidades que a relação familiar traz consigo.

Em síntese, os problemas ligados à relevância jurídica da família de fato repousam sobre as seguintes considerações: se o intérprete não pode simplesmente estender por analogia a norma vigente para a família de fato, equiparando-a no tratamento jurídico com a família legítima - porque, assim o fazendo, violaria a liberdade daquela comunidade natural que entende fundar-se no consenso duradouro e não quer comportar-se segundo o direito do casamento - não pode abster-se de atribuir a relevância jurídica necessária para assegurar que as posições individuais dos componentes mais fracos recebam também com os instrumentos da lei uma adequada tutela.

A tendência em reconhecer relevância autônoma para a família de fato encontra-se, em primeiro lugar, na previsão do artigo 317-bis CC, que atribui à convivência entre homem e mulher não unidos por casamento e genitores de um filho o exercício do poder parental substancialmente idêntico àquele que vale no âmbito da família legítima, assim como a possibilidade de requerer a intervenção do juiz para dirimir os conflitos entre eles relativos ao próprio poder.

Uma previsão, portanto, que, na precisa intenção de tutelar os interesses dos filhos, estabeleceu uma relação jurídica de natureza familiar entre o homem e a mulher que convivem fora do casamento e atribuiu à família natural uma relevância desconhecida no passado.

Isso não permite concluir que, da codificação do artigo 317-bis CC, tenha sido introduzida uma regra que, se não é completa, ao menos, é satisfatória à família de fato; falta hoje uma regra harmônica da matéria (sobre esse ponto, envia-se ao item 7).

Por outro lado, é ao trabalho do direito que se deve a elaboração dos princípios e das regras que, fundamentalmente, reconheceram a relevância jurídica das uniões livres em todos os casos nos quais parecia injustificado não submeter os seus protagonistas às normas ditadas de modo explícito pelos cônjuges legais.

Algumas leis, ainda que de maneira fragmentária e desarmônica, fazem, muitas vezes, referência aos fenômenos de convivência não conjugal: assim, a exemplo, no âmbito da legislação social e previdenciária, a já citada Lei $n^{\circ} 405 / 1975$, instituída pelos consultores familiares, indica entre aqueles que têm direito à assistência (não apenas "os indivíduos" e "as famílias", 
mas também "os casais", casados ou não), como destinatários dos serviços que o centro de orientação oferece em relação à sexualidade, à maternidade e à primeira infância. Por sua vez, a Lei no 194/1978, que disciplina a interrupção voluntária da gravidez, prevê que a "pessoa indicada como pai do concebido" esteja presente no procedimento e, dos mesmos trabalhos legislativos, emerge com clareza como o uso de tal genérica expressão estava especificamente conectada à exigência de evitar discriminação entre cônjuges ou companheiros.

Merece ser lembrada, também, a norma que consente ao detido obter permissões para se ausentar da prisão, com o fim de prestar assistência não só aos familiares, mas também ao próprio companheiro (artigo 30 , parágrafo $1^{\circ}$, da Lei $n^{\circ}$ 354/1975). Assim também a nova elaboração do artigo 199 CPP, que estende a faculdade de abster-se de não testemunhar para quem, ainda que não seja cônjuge do réu, convive com este (sobre esse ponto, a Corte Constitucional, com a Sentença $n^{\circ} 6 / 1977$, havia justificado essa referência somente aos parentes próximos do réu, contido na formulação original do artigo). Enfim, na legislação sobre a sociedade cooperativa de propriedade indivisível, deve-se lembrar como o artigo 17 da Lei $n^{\circ}$ 179/1992 reconhece o direito do companheiro de substituir o de cujus no controle da sociedade, caso não existam cônjuge e filhos menores, desde que a união estável seja certificada por registro em cartório e tenha sido iniciada ao menos dois anos antes do momento da morte.

É evidentemente difícil uma avaliação sintética das orientações do direito constitucional que não equipara nunca a família de fato à família legítima, mas, antes, se observa uma progressiva afirmação dos direitos advindos de uma relação estável e duradoura na base da relevância implícita que, em tal circunstância, se origina de uma formação social na qual se desenvolve a personalidade do homem apta a exercer as funções fundamentais de socialização, tutelada pelo artigo $2^{\circ}$ da Constituição. Isto é, a família de fato está apta a desenvolver uma função de socialização seja na relação entre o casal seja na relação entre pais e filhos, identifica aquela exercida pela família legítima.

Assim, por exemplo, a Corte, chamada muitas vezes a se pronunciar acerca da aplicabilidade de normas em relação a locações de imóveis aos conviventes more uxorio (normas que na formulação literal parecem estar limitadas somente aos membros da família legítima), com a primeira Sentença $n^{\circ} 45 / 1980$, nega ilegitimidade do direito de prorrogação da locação, pela falta de previsão, a quem vivia em união estável more uxorio com o locatário de cujus. Sucessivamente, muda radicalmente a própria orientação, com duas sucessivas sentenças, estendendo ao companheiro do locatário o direito de sucedê-lo no contrato de locação em caso de morte (Sentença no 404/1988), dando-Ihe o direito ao recebimento de alojamento de construção residencial pública (Sentença n 559/1989). 
No que diz respeito ao núcleo argumentativo dos pronunciamentos em questão, deve ser procurado um reconhecimento do papel constitucional do direito à habitação, entendido como direito social enquadrável entre os direitos invioláveis do homem a que se refere o artigo $2^{\circ}$ da Constituição e, que, somente implicitamente, produz os seus efeitos sobre a relevância jurídica da família de fato.

A Corte, em síntese, mantém firme a distinção entre união estável baseada no affectio quotidiano liberadamente e a qualquer momento revogável - e relação conjugal; essas situações são tão diferentes a ponto de impedir a sua automática assimilação com o fim de deduzir disso uma exigência constitucional de igualdade de tratamento (Ordenamento n ${ }^{\circ}$ 204/2003, mas também nas Sentenças $n^{\text {os }} 313$, 352 e 491/2000).

Por outro lado, a tendência de relacionar à união estável more uxorio a existência de interesses dignos de tutela, à luz da relevância dada às formações sociais do artigo $2^{\circ}$ da Constituição, está presente em outras sentenças: na Sentença $n^{\circ}$ 30/1983 que se refere à cidadania do companheiro ou, ainda, nas Sentenças $n^{\text {os }} 198$ e 237/1986 que tratam da adoção e da aplicabilidade às uniões estáveis extraconjugais de normas do direito penal.

Resta considerar que, em qualquer discurso sobre a família natural ou a família de fato, o aspecto mais relevante diz respeito à tutela dos filhos nascidos fora do casamento, mas sobre esse ponto falaremos na parte 6 .

\section{A IGUALDADE MORAL E JURÍDICA DOS CÔNJUGES E A UNIDADE DA FAMÍLIA}

As questões fundamentais que se relacionam com a tutela constitucional da família, nos termos até agora examinados, são representadas pela posição da mulher no seu interior e, como veremos no parágrafo seguinte, nas relações que dizem respeito à filiação natural.

O parágrafo $2^{\circ}$ do artigo 29 da Constituição sanciona expressamente 0 princípio da igualdade moral e jurídica dos cônjuges como regra fundamental na organização das relações familiares.

A fórmula da igualdade moral e jurídica representa, portanto, uma precisa escolha legislativa constitucional com o fim de produzir importantes efeitos sobre todos os aspectos da vida dos cônjuges: das relações patrimoniais a todas as relações inerentes às decisões familiares até compreender, em termos ainda mais amplos, tudo aquilo que envolve o respeito da personalidade e da dignidade de cada um. Deve ser lembrado, também, percorrendo um longo debate desenvolvido na doutrina jurídica italiana, que não poderia ser atribuído ao parágrafo $2^{\circ}$ do artigo 29 da Constituição força revogatória em relação à preexistente legislação ordinária, ${ }^{13}$ ainda que se reconheça o valor não meramente programático, mas preceptivo da disposição em questão.

${ }^{13}$ BESSONE, Mario. Commento agli Articoli 29, 30 e 31 Costituzione... 
Isso deriva das relações entre as fontes do nosso ordenamento e da configuração da revogação implícita como critério de superação das contradições entre fontes de mesma hierarquia e conflitantes ${ }^{14}$ e pela impossibilidade de resolver em termos de revogação a inconstitucionalidade sobrevinda das leis ordinárias preexistentes (Corte Constitucional, Sentença no 1/1956).

Foi decisiva a obra da Corte Constitucional porque, como já visto, permitiu excluir do nosso ordenamento as normas legislativas em contraste com os preceitos constitucionais e realizar a desejada intervenção da reforma.

Por outro lado, estabelecida a regra da igualdade moral e jurídica da mulher em relação ao marido, o próprio artigo 29 da Constituição permitiu ao legislador a tarefa de limitar a igualdade dos cônjuges, garantindo a unidade familiar. A Constituição permite o estabelecimento de uma série de limites para a regra da igualdade desde que tenham no seu título a necessidade de garantir "a unidade familiar", ou seja, podemos dizer, o ordenado e, portanto, não desagregado funcionamento do núcleo familiar.

Todavia a individualização desses limites - mesmo sendo uma questão delicada e tendo-se sempre em consideração o respeito a outros interesses constitucionalmente protegidos - é delegada ao legislador ordinário que, com a reforma de 1975, Ihes deu uma interpretação conforme as instâncias reformadoras. Porém podia não tê-la feito no sentido da própria Constituição. ${ }^{15}$

Percebe-se como o âmbito de tal possível intervenção mudou no tempo em relação à evolução do conceito de igualdade. Quanto mais significativa e efetiva tornou-se a referência a esse princípio (também por envolver a consciência social e civil), tanto mais se tornaram raras as intervenções limitativas do legislador, e mais incisivo foi o papel da Corte Constitucional ao declarar a inconstitucionalidade das normas limitadoras de igualdade moral e jurídica dos cônjuges sem uma real justificação na exigência de proteger a unidade familiar.

Mas resta, na difícil determinação da relação entre "unidade" e "igualdade", a procura de um ponto de equilíbrio e de coexistência entre ambos no âmbito da comunidade familiar.

Em termos gerais, a paridade dos cônjuges conduz ao princípio de igualdade sancionado pelo artigo $3^{\circ}$ da Constituição - onde se proíbem discriminações na dignidade social e na igualdade jurídica que derivem de distinções de sexo - que, portanto, não pode não produzir os seus efeitos e não aplicar-se também ao casamento (Corte Constitucional, Sentença $n^{\circ}$ 201/1972); isso, não obstante a proibição ao legislador de dispor de um tratamento jurídico diferente por razões de sexo, encontra, como exceção ao princípio geral, o limite relativo à garantia da unidade familiar.

\footnotetext{
${ }^{14}$ CRISAFULLI, Vezio. Lezioni di Diritto Costituzionale. Padova, 1993.

${ }^{15}$ SPAGNA MUSSO, Enrico. Diritto Costituzionale...
} 
Em outros termos, no artigo 29 da Constituição - norma constitucional que estabelece expressamente o princípio da igualdade perante a lei é reafirmada a ilegitimidade de todas as previsões revogatórias do próprio princípio que não estão de acordo com as exigências específicas de garantia da unidade familiar.

A relação entre "unidade" e "igualdade" pode ser resolvida atribuindo à unidade a exclusiva função de limitar a igualdade. Refutada a atribuição de um valor exclusivamente formal, de limite negativo, da igualdade que esteja de acordo com a Constituição, a unidade pode ser interpretada como instrumento para atuação "do pleno e integral respeito à personalidade dos cônjuges e da prole: o fundamento a qual se inspira para uma interpretação moderna das exigências e da tutela do sujeito no âmbito da comunidade familiar". ${ }^{16}$

Em sentido parcialmente diferente, considerou-se como sendo admissíveis somente as limitações funcionais para a garantia da unidade familiar, sendo estas suscetíveis de valor nas relações dos cônjuges em que ambos são responsáveis por comportamentos que podem comprometer a unidade da família. ${ }^{17}$

Ou ainda, enfatizou-se como a igualdade absoluta contrastaria, de maneira inconciliável, com a unidade. ${ }^{18}$

Como se vê, não é fácil precisar em que sentido o princípio da igualdade é integrado pelos "limites" introduzidos para garantir a unidade familiar. O debate sobre a prevalência da unidade na igualdade, ou vice-versa, foi superado pelo legislador mediante a regra do acordo, introduzindo um modelo de família governado pelo consenso.

Nessa perspectiva, a procura de um efetivo e perfeito equilíbrio entre a igualdade e a unidade não deve, e não pode, construir-se nem sob critérios trazidos do princípio da hierarquia (e, portanto, de autoridade), nem sob critérios de distribuição de poderes e funções entre os cônjuges, mas sob liberdade igual e responsabilidade dos cônjuges capaz de assegurar formas de comunhão espiritual e de solidariedade familiar e, enfim, interpretar a unidade como "síntese de valores espirituais"; fórmula que dificilmente pode encontrar expressão imediata em normas jurídicas.

\section{A POSIÇÃO CONSTITUCIONAL DOS FILHOS NA FAMÍLIA: FILHOS LEGÍTIMOS E FILHOS NATURAIS}

Em relação aos filhos, o parágrafo $1^{\circ}$ do artigo 30 da Constituição afirma o dever-direito dos pais de mantê-los, instruí-los e educá-los, "mesmo se nascidos fora do casamento".

\footnotetext{
${ }^{16}$ PERLINGIERI, Pietro. Commento alla Costituzione Italiana...

${ }^{17}$ MORTATI, Costantino. Istituzioni di Diritto Pubblico. vol. II. Padova, 1975.

${ }_{18}$ MODUGNO, Franco. L'eguaglianza nell unità della Famiglia. In. Studi in tema di Diritto di Famiglia. Milano, 1967.
} 
São evidentes os efeitos que tal dispositivo constitucional produz, seja reforçando o valor da paridade dos cônjuges, seja, sobretudo, em razão da nitidez da fórmula usada que estendeu as obrigações dos pais à filiação natural. O dado constitucional relevante ao qual se ligam essas obrigações é, portanto, a filiação em si, sem que, neste sentido, releve a situação jurídica em cujo âmbito aconteça, prescindindo de qualquer forma de reconhecimento de status. ${ }^{19}$

Significativa também é a estreita conexão entre a afirmação do dever e a correlativa decisão do direito.

Mas a inovação do parágrafo $1^{\circ}$ do artigo 30 da Constituição é redimensionada pelo sucessivo parágrafo $3^{\circ}$, que remete à lei a tarefa de ditar normas que assegurem aos filhos nascidos fora do casamento tutela jurídica e social compatível com os direitos dos membros da família legítima. Pelo disposto na Constituição, podem-se, assim, inferir dois princípios: a inadmissibilidade da plena igualdade entre filhos nascidos no âmbito do casamento e filhos nascidos fora deste; a obrigação do legislador de garantir uma proteção jurídica eficaz aos filhos nascidos fora do casamento, "compatível com os direitos da família legítima". Essa última expressão, que, como se enfatizou, independentemente das várias interpretações propostas pela doutrina e pela jurisprudência, freia a obrigação antes referida com limites não seguramente identificáveis na sua legitimidade constitucional. Mesmo que se pudesse propor um válido critério interpretativo de "compatibilidade", permaneceria a dificuldade de estabelecer concretamente se recorre ou não aos extremos à categoria interpretativa elaborada de modo geral.

A atribuição de igualdade entre filhos legítimos e filhos ilegítimos, contrariada em um primeiro momento por interpretações restritivas da doutrina e pela própria jurisprudência constitucional (como exemplo a Sentença $n^{\circ}$ 54/1960), atuou em uma série de declarações de inconstitucionalidade, corrigindo em muitos pontos a disciplina de elaboração de códigos, adequando-os ao preceito constitucional (em particular, no sentido de uma acrescida tutela patrimonial, sobretudo, na questão sucessória: assim as Sentenças $n^{\text {os }}$ 205/1970; 82/1974) e, posteriormente, na muito citada reforma do direito de família de 1975, na qual se pode dizer que se acrescentou a paridade de tratamento dos filhos legítimos e dos filhos naturais reconhecidos.

Tal igualdade que, certamente deixou mais livre a escolha entre casamento e união estável - não mais condicionada à exigência de assegurar aos filhos um status mais favorável - também preservou algumas diferenças no perfil das relações entre filiações naturais e legítimas. A referência a "qualquer tutela jurídica e social" dos filhos naturais comporta a necessidade de uma tutela plena e completa em relação a estes, apresentando, porém, um diferente alcance nas relações com os terceiros e na sociedade em geral.

${ }^{19}$ PERLINGIERI, Pietro. Commento alla Costituzione Italiana...; GIORGIANNI, Michele. Problemi Attuali di Diritto Familiar...; BESSONE, Mario. Commento agli Articoli 29, 30 e 31 Costituzione... 
De fato, enquanto a família legítima existir, o alcance da tutela dos filhos naturais conserva-se inalterado na sua extensão sobre o plano das relações patrimoniais (não muda o direito dos filhos, ainda que nascidos fora do casamento, de ser mantidos, instruídos e educados como os filhos legítimos), podendo sofrer uma diminuição caso se refira às situações de valor afetivo ou espiritual.

Os efeitos da previsão do parágrafo $3^{\circ}$ do artigo 30 da Constituição definem o significado do parágrafo $1^{\circ}$. Tais efeitos, porém, devem referir-se exclusivamente à posição familiar dos filhos ilegítimos em relação à unidade e à coesão da família legítima.

Além disso, as limitações aqui já expostas foram superadas, também, pela condescendência dos membros da família legítima (nesse sentido, versa a Sentença $n^{\circ}$ 237/1974). No ponto, a própria Corte excluiu o reconhecimento, na vigente disposição constitucional, de um direito dos filhos legítimos de "impedir que outros adquiram o mesmo estado de filhos legítimos, com os direitos e os deveres inerentes a esta condição" (Sentença no 97/1979).

Independente das relações que se instauram - no que diz respeito à existência da família legítima - é constitucionalmente imprescindível a plena e integral atuação do princípio da igualdade jurídica e social dos filhos naturais em relação a terceiros e à sociedade em geral. Neste sentido, também é a previsão disciplinada no artigo 31 da Constituição ("a república protege a maternidade, a infância e a juventude, favorecendo os institutos necessários para tal escopo") que assume um importante valor compensatório em razão da tutela indiferenciada, sancionada por esse dispositivo, que se depreende implicitamente do princípio da igualdade dos filhos naturais.

Concluindo, valorizada por uma leitura lógico-sistemática da norma constitucional, a afirmação da "dignidade social igualitária" a todos os cidadãos sem distinção "de condições pessoais e sociais" (artigo $3^{\circ}$ da Constituição) e do valor primário da pessoa (artigo $2^{\circ}$ da Constituição) liga-se à "tutela social" sancionada pelo mesmo artigo 30 da Constituição.

\section{A FAMÍLIA NA DIMENSÃO EUROPEIA}

É, sem dúvida, verdade que as modificações normativas que intervieram em nível europeu e a inevitável comparação entre os institutos jurídicos adotados por diferentes ordenamentos nacionais influenciaram inevitavelmente a evolução da disciplina da família também na Itália.

Prova disso é que hoje, na Europa, as soluções legislativas adotadas em matéria de ordenamento familiar tendem a convergir, refletindo princípios comuns - basta pensarmos nas relações entre os cônjuges (patrimonial, separação e divórcio) e entre pais e filhos mesmo se nascidos fora do casamento ou, ainda, na própria reavaliação da autoridade no interior da família.

Por outro lado, porém, o conceito de família legítima fundada no casamento, como modelo normativo dominante nos sistemas jurídicos ocidentais, não é 
mais, ao menos do ponto de vista da realidade social, o único parâmetro de referência. Emerge a relevância assumida em todos os países europeus pela família de fato, seja do ponto de vista quantitativo (como as recentes estatísticas demonstram), seja pela complexidade com a qual hoje os fenômenos se apresentam. Quando se fala de família de fato não se faz referência somente à convivência de pessoas de sexo diferente, mas também à convivência de pessoas do mesmo sexo. Estabeleceu-se, assim, uma variedade de modelos alternativos em relação aos quais, em muitos países europeus, deu-se uma resposta legislativa no que diz respeito também ao reconhecimento dos casais homossexuais.

Ao lado dos casamentos tradicionais estão previstas fórmulas institucionalizadas de reconhecimento de relações afetivas: as uniões ou coabitações de casais heterossexuais (como na Bélgica, na França, na Escócia e no Reino Unido) e, ainda, às uniões homossexuais (como na Holanda, na Dinamarca, na Suécia e na Alemanha).

Dentro desse quadro, é que a perspectiva europeia de uma tendência de harmonização entre os ordenamentos dos Estados-Membros adquire uma nova dimensão à luz do Tratado que institui uma Constituição para a Europa. Firmado em Roma, em 29 de outubro de 2004, o Tratado propõe, novamente, ao intérprete muitas questões sobre o direito e os seus limites.

Como já observamos, o "debate italiano" caracteriza-se por uma grande prudência no reconhecimento de um fundamento constitucional que deve oferecer uma adequada tutela às pessoas que preferem o modelo de convivência e o respeito à liberdade aos que decidem não se unir pelos laços do matrimônio. É verdade que a resistência mostrada pelo ordenamento italiano, no que concerne a uma disciplina da família de fato, se explica, também, em razão da preocupação com uma inevitável extensão da disciplina às uniões entre pessoas do mesmo sexo.

O tema da família - concernente à abordagem tipicamente constitucional - põe ao intérprete a questão de decidir se é realmente possível proceder a uma leitura exclusiva da dimensão familiar, que certamente se expande quando a família fundada no casamento - objeto de garantia constitucional passa, também, a considerar legítimas as uniões de fato. No entanto, surge o risco de esquecer-se a ideia de família como lugar de aprendizagem de valores e de desenvolvimento da personalidade, que representa um elemento qualificativo da nossa experiência constitucional.

O Tratado instituído na Constituição europeia acolhe integralmente, como sabido, o texto da Carta de Direitos Fundamentais, proclamado em Nice, em dezembro de 2000 , no qual o artigo $9^{\circ}$ estabelece que "o direito de se casar e o direito de constituir uma família são garantidos segundo as leis nacionais que disciplinam o seu exercício" (hoje artigo II-69 TCE).

A formulação é caracterizada pela menção às legislações nacionais, que disciplinam de maneira diferente as diversas formas de liberdade do casamento, 
deixando uma margem suficientemente ampla e capaz de garantir a coexistência de ordenamentos, mesmo que significativamente diferentes. Seguindo uma interpretação restritiva, poder-se-ia sustentar que nada muda para o ordenamento italiano que, nesta disposição, garante o casamento segundo a própria normativa. Observemos, no entanto, a distinção entre direito de se casar e direito de constituir uma família: o último evidentemente não está subordinado ao primeiro, constituindo-se uma formulação ampla, que inclui a disciplina das uniões de fato e também das uniões de pessoas do mesmo sexo.

Há de se ter presente que a interpretação conjunta, lógico-sistemática, do artigo II-69 TCE com os artigos II-80 (princípio da igualdade formal em nível comunitário) e II-81 (proibição de discriminação na orientação sexual) conduz à afirmação de que deve ser garantida, para qualquer cidadão de uma comunidade, de modo igualitário e sem discriminações, a liberdade de casar-se segundo as legislações nacionais. ${ }^{20}$

E aqui está o ponto central da questão: uma vez que a legislação de muitos Estados-membros prevê formas de reconhecimento e tutela às uniões de fato heterossexuais ou homossexuais, surgem discriminações, que podem derivar da nacionalidade dos diferentes cidadãos da comunidade, em evidente violação à proibição de discriminação com base na nacionalidade, princípio fundamental do ordenamento comunitário. Essa circunstância é cada vez mais complicada, ao se considerar que a cidadania europeia compreende 0 direito à livre-circulação e estadia em todos os Estados-membros, sem enfrentar, neste particular, os efeitos da aplicação do direito internacional privado.

A busca por uma uniformização da disciplina ligada ao progresso da integração na comunidade requererá do nosso ordenamento a procura das soluções legislativas que (sem ignorar os conteúdos mais peculiares e fundadores dos valores da experiência constitucional e não esperando que as reformas nos venham impostas pelo direito europeu), permitam diminuir a distância da legislação e da sociedade e, enfim, encontrar soluções capazes de oferecer uma proteção, em certo grau de garantia, a sujeitos que estão, ao menos formalmente, desprovidos de amparo.

\section{REFERÊNCIAS BIBLIOGRÁFICAS}

AMATO, Giuliano; BARBERA, Augusto. Manuale di Diritto Pubblico. Bologna, 2001.

BARBERA, Augusto. Commento all articolo 2 Costituzione. In. Commentario della Costituzione, a cura di Giuseppe Branca. Bologna, 1975.

BARCELLONA, Pietro. Famigli (dir. civ.). In. Enc. dir., XVI. Milano, 1967.

BARILE, Paolo. Il Soggetto Privato nella Costituzione Italiana. Padova, 1953.

. Eguaglianza dei Coniugi ed Unità della Famiglia. In. Scritti Giuridici in Memoria di Vittorio Emanuele Orlando. Padova, 1957.

${ }^{20}$ CELOTTO, Affonso. La Libertà di Contrarre Matrimonio fra Costituzione Italiana e (progetto di) Costituzione Europea: spunti di riflessione. In Famiglia, 2/2004. 
Società. 1974.

L`eguaglianza dei Coniugi nella Giurisprudenza Costituzionale. In Diritto e Diritti dell uomo e Libertà Fondamentali. Bologna, 1988.

BESSONE, Mario. Commento agli Articoli 29, 30 e 31 Costituzione. In. Commentario della Costituzione, a cura di Giuseppe Branca. Bologna, 1976.

BESSONE, Mario; ALPA, Guido; D`ANGELO, Andrea; FERRANDO, Gilda; SPALLAROSSA, Maria. La Famiglia nel Nuovo Diritto. Bologna, 1997.

BIAGI, Roberta. Famiglia e Costituzione. Milano, 1989.

CELOTTO, Affonso. La Libertà di Contrarre Matrimonio fra Costituzione Italiana e (progetto di) Costituzione Europea: spunti di riflessione. In Famiglia, 2/2004.

CRISAFULLI, Vezio. Lezioni di Diritto Costituzionale. Padova, 1993.

CRISAFULLI, Vezio; PALADIN, Livio. Commentario breve alla Costituzione. Padova, 1990.

ESPOSITO, Carlo. Famiglia e Figli nella Costituzione Italiana. In. La Costituzione Italiana. Padova, 1954.

GIORGIANNI, Michele. Problemi Attuali di Diritto Familiar. In. Studi in Memoria di Filippo Vassalli. Torino, 1960.

GRASSETTI, Cesare. I Principi Costituzionali Relativi al Diritto di Famiglia. In. Commentario Piero Calamandrei. Roma, 1949.

MODUGNO, Franco. L’eguaglianza nell unità della Famiglia. In. Studi in Tema di Diritto di Famiglia. Milano, 1967.

MORTATI, Costantino. Istituzioni di Diritto Pubblico. vol. II, Padova, 1975.

PERLINGIERI, Pietro. Commento alla Costituzione Italiana. Napoli, 1997.

PROSPERI, Francesco. La Famiglia non Fondata sul Matrimonio. Napoli, 1980.

RESCIGNO, Pietro. La Tutela dei figli nati fuori del Matrimonio. Riv. dir. matr., 1965.

. Persona e Comunità. Bologna, 1966.

. Riforma del Diritto di Famiglia. Padova, 1972.

. Manuale del Diritto Privato Italiano. Napoli, 1996.

SESTA, Michele. Lezioni di Diritto di Famiglia. Padova, 2005.

SPAGNA MUSSO, Enrico. Diritto Costituzionale. Padova, 1992.

UNGARI, Paolo. Storia del Diritto di Famiglia in Italia. Bologna, 1974. 